9 out of the 84 operations needed a second dressing; the dressing first applied being one of salicylic or "salufer" wool held in position by a gauze bandage.

Out of 63 divisions of the femur for genu valgum, in only 1 was any,pus seen, and in that case, a small piece of necrosed bone, about the size of a sixpence, came away, but the patient ultimately did well.

Of the tibial cases, two suppurated and required a number of dressings, and in one of these the ends of the bone had to be refreshed. In these two cases the saw was used instead of the chisel. Except in the three cases which suppurated, the temperature was normal. The ultimate results, so far as the straightness of the limbs is,concerned, (have been very satisfactory ; but it was found that unless instruments were ordered there was usually a tendency to a recurrence of the deformity when the patients returned tu their old mode of life; hence, after the first few cases, instruments were always ordered to be worn from about the eighth week, that is from the time of removing the plaster-ofParis dressing, which was usually applied during the second week, when the cases were treated as out-patients. The ages of the patients varied from 4 years to 40 , but the greater number were young adults. Syrup of phosphate of iron was generally given for some time after the operation, and if possible the patient was sent to a convalescent home or into the country.

The presence of the considerable numbers of deformed limbs seen in most of our large towns, for instance Glasgow and Leeds, is a standing reproach to the public authorities and to preventive medicine. I would suggest that more attention ought to be paid to the dwellings of the poor, overcrowding should be prevented, back to back houses should not be allowed, efficient sanitary arrangements should be compulsory, and no chamber should be permitted to be used as a dwelling room that would not allow of the free entrance of light and fresh air.

I cannot help thinking, that ignorance has more to answer for than negligence, in the greater number of these cases, and that if parents were instructed in the art of correctly feeding their progeny, and were educated to be ashamed of seeing their children grow up deformed (when by a little attention in the incipient stages, deformity might be prevented), a great step would be taken in the right direction.

Fortunately, however, as the foregoing cases show, it is now possible, thanks to Dr. Macewen and to the antiseptic system of treating wounds, to correct these deformities by division of the bones, just as easily and efficiently as subcutaneous tenotomy can correct cases of talipes.

\section{THE FIBROMATOUS PROSTATE.}

BY REGINALD HARRISON, F.R.C.S.,

Surgeon to the Liverpool Royal Infirmary, and Lecturer on Clinical Surgery in the Victoria University.

The term fibromatous prostate seems to me to represent better than any other that condition of the part which most frequently brings it under the attention of the surgeon. Ordinary hypertrophy, where the relative proportions of the constituents are preserved, may be said to be the acquired disposition of the prostate in a considerable proportion of elderly males, to whose comfort we may infer it contributes. In the examination of men of sixty years of age or thereabouts, many of us must have been frequently struck, not only with the size the part has attained, but also by the immunity of the individual from symptoms of urinary incompetency. But in these persons, though the area of the prostate is increased as determined by the touch, there is usually no evidence that the part has undergone structural substitution. Nor is it at all necessary or consequential that such a hypertrophic alteration in bulk should give place to a new order of things, and that disturbed function must ensue. It seems to me, from a good many years' clinical observation in reference to this point, that no inconsiderable proportion of persons who have large prostates live about as long and as comfortably as others who are not so provided. Is the accession of urinary symptoms in persons so circumstanced to be attributed to what might be called the accidents of living, or to the development of tolerably well-defined changes in the hypertrophied part itself? Without referring to points which I have already discussed at length, " I may say that my observations lead me to believe that it is only when the hypertrophied prostate becomes the fibromatous prostate that it is capable of arousing those symptoms of chronic irritation and obstruction with which we are familiar in persons of advancing years. The liability to these and sundry complications arising out of them is largely determined by the elements entering into the composition of the part involved. That a muscular prostate is capable of adapting itself to circumstances where a fibrous one is not, is, I think, a statement most of us would at once be inclined to admit. Reviewing what I have noticed of the symptoms which are assigned to senile prostatic enlargement, I cannot recall an instance where there was not evidence when looked for, not of structural increment alone, but of fibrous predominance. In some of these careful examination after death has shown us that fibrous tissue has largely invaded the muscular apparatus of the prostate. This substitution or proliferation is in practice observed in a variety of ways, which may be briefly illustrated.

The slightest forms of fibromatous prostate are often met with in elderly men in connection with sudden attacks of retention of urine, which conventionality assigns to indulgence in alcohol or sexual excess, often without sufficient evidence thereof. Exposure to wet or cold, such as sitting on a damp seat, is, I believe, a far more frequent cause, In this way some swelling of the part occurs, and retention of urine ensues. A few days' careful catheterism and warmth to the perineum usually put matters to rights again. Examination of the prostate with the finger, from the rectum, shows by the presence of indurations that it has undergone other alterations than those which could be included under the term hypertrophy. Taking another class of cases, I refer to those where elderly persons suffer from more or less irritability of the bladder, with excessive mucous exudation. Such individuals are often tormented by day and night to a degree which neither Nature nor the catheter can appease. Rectal examination shows not only that these men have, like a great many others, large prostates, but that they also have hard, knotty ones, which offer considerable resistance to the finger. In the last place let me illustrate from that class of cases where the prostate, by its fibrous excrescences, simulates stone. Here not only have we intense vesical irritation and inflammation due to the growth having encroached upon the interior of the bladder, but we have a secretion of mucus far exceeding anything that is usually seen in connection with stone in the bladder. Again, the catheter and the finger show that we have a still more advanced form of fibrous degeneration to contend with.

The outcome of these remarks, so far as I have observed, is that a large prostate may, functionally, mean very little. When, however, there is evidence that structural alteration of the kind indicated has taken place in it, the liability to the accession of urine symptoms is greatly increased. Further, in these changes we shall probably find an explanation not only for the development of symptoms which the commoner form of prostatic hypertrophy does not afford, but also, I believe, for certain alterations which have been observed in the physiological action of drugs upon the part.

In practice I have found that the structural condition of the prostate in the elderly often furnishes the best means for prognosticating events, so far as the urinary apparatus is concerned, just as a physical examination of the heart will enable the physician to forecast the future of the circulatory system.

These observations, bearing upon the pathology of the enlarged prostate, will probably find full expression in connection with the views I have advanced in my recent Lettsomian Lectures, as to the muscular power of the prostate in retaining and storing urine.

\section{NOTES OF A CASE OF ABSCESS IN THE GROIN CONTAINING THE VERMIFORM APPENDIX.}

By W. D. SPANTON, F.R.C.S.Ed., Surgeon to the North Staffordshire Infirmary

AN unmarried lady, aged 62 , consulted me in October, 1888, for an abscess of the right groin, which was so painful as to call for relief. She stated that her general health had been good, and that two years before, in carrying a heavy basket, she felt something give way in the right groin. It caused pain at the time, and a small swelling appeared shortly afterwards, but as it occasioned only slight inconvenience, no further notice was taken 
of it, and nothing done for its relief. In August last the surface of the swelling became red and inflamed, and shortly afterwards the skin gave way, followed by discharge of dark-coloured thin pus, not constantly, but at frequent intervals.

At the time I examined it there was an erysipelatous blush over the upper part of the thigh, with two sinuses discharging dirtylooking pus in small quantity. Over the crural ring was a hard mass about the size of one's thumb, which hardly felt like glands, nor had it the sensation of being a hernia, unless an irreducible, omental one. A probe was passed downwards and inwards for nearly three inches, evidently into an abscess-cavity. After subduing the inflamed state, I proposed to operate, and deal with what I might find as then seemed best. To this the patient assented, and on November 4th, under chloroform, I first laid open the abscess-cavity, which was covered with thick lining membrane like that of an ordinary chronic abscess. This I cut away by scraping and scissors, and then found that the hard portion consisted of some absorbent glands thickened and hard and matted together, lying on the internal saphena vein over the mouth of the crural ring. Proceeding carefully, I came upon something which was not gland, and did not appear like bowel or hernial sac; so I dissected away the glands, and found a minute opening, which proved to be the tip of the vermiform appendix. I could draw it down for about two inches easily, but being anxious not to open the peritoneal cavity, I refrained from examining further than to pass my finger through the crural canal. I then found that the appendix had come down behind the peritoneum; the peritoneal cavity was intact, and there was, of course, no peritoneal covering to the appendix. It was, in fact, a retro-peritoneal hernia of the appendix only, through the crural ring.

I placed a catgut ligature on the divided end of the appendix, and left it in the crural canal, as it appeared to be empty and perfectly healthy. The wound was closed in the ordinary way, a drainage-tube inserted, and in a few days it had solidly healed, except a small sinus at the upper part, which is now almost closed.

The case seems to me worth relating for several practical reasons. It illustrates what one meets with so often-the uncertainty and the dissimilarity of the constitution of almost all groin swellings, and the wisdom of reserving a very positive opinion as to their nature until one has seen the inside of them. So far as my experience extends, and so far as I can find recorded, a femoral hernia of this kind must be extremely rare. I have had some cases where the cæcum and vermiform appendix formed large inguinal herniæ (one on the left side, curiously enough), but never before a femoral one. It would appear that in this instance the tip of the appendix had become glued by inflammation to the glands at the crural opening, and by the escape of fæcal fluid from a minute opening caused the abscess to form around, inasmuch as the glands had not suppurated. The entire absence of any indication of a hernial sac dispelled the idea I had at first that the hard mass might be omental; though it is, of course, easy to see why there should be no peritoneal covering in this case.

I think the result shows that nothing would have been gained by the mere laying open of the abscess, and that the course I took was the best to take under the circumstances.

\section{CLINICAL MEMORANDA.}

\section{TIIREE CASES OF PURPURA RHEUMATICA.}

DR. DUTT's notice of this variety of purpura, in the JouRnal of December 1st, recalls to my memory three cases which I had under my care last winter: Miss M., aged 22; Miss Y., aged 38; and Mrs. W., aged 60 . All three commenced with a severe attack of acute rheumatism, and were placed under the salicylic treatment for about ten days, when, the fever and pain having subsided, a mixture of bicarbonate of potash and cinchona was substituted. About the eighteenth day, large red spots, ranging from half an inch to an inch in diameter, appeared on the tibial and ulnar surfaces. There was considerable gastric disturbance, vomiting, and constipation, with some little diarrhœa, and an average temperature of $102^{\circ} \mathrm{F}$. I ordered an effervescing mixture and large doses of Hunyadi Janos water each morning; a generous diet, with lime-juice and soda-water to allay thirst, which in the case of Miss $Y$. was excessive. The epots were dusted with flour, and covered with cotton wool, but in Miss M.'s case lead lotion had to be substituted, the heat and pain were so great. As soon as the gastric disturbance was allayed, I gave them iron tonics.

All three have recovered, are now free from rheumatism, with hearts unaffected; in fact, Miss Y. returned from Bournemouth about a month ago, saying she never felt better in her life, which I attribute to the course of hot sea-water baths she has undergone.

As I have never seen any cases like these before in practice, I should very much like to see the pathology of this peculiar disease worked out. VINCENT J. MAGRANE, L.K.Q.C.P. and L.R.C.S.I.

The Leys, Darlaston, Staffordshire.

\section{GYNÆCOLOGICAL MEMORANDA.}

PAPILLOMA OF VAGINA IN A CHILD.

In the JounNaI of September 16th, in a special note, reference is made to some cases already published of "Sarcoma of the Vagina in Children." The notes of the following case may prove of interest in connection with those referred to.

G. C., aged 2 years 7 months, was admitted May 14th, 1881 The mother stated that about two months ago she noticed a "lump in her privates," when washing her ; it was dark in colour, did not bleed, and the child did not suffer pain. She was seen by a medical man in the town, who applied a ligature to a portion of the growth. The swelling speedily returned, but has become much more evident during the last week. When seen by me the swelling was protruding from the vagina, and was judged to be about the size of a small " fist," dark in colour, with offensive odour and bloody discharge. Urine was passed with difficulty; the bowels had acted the day before admission. A catheter was passed into the vagina above and below the mass, which led to some escape of bloody pus. The temperature was normal; she had vomited food twice since coming into hospital.

May 16th. Chloroform was given, and an examination made by passing the finger as far as was possible into the vagina, and by the help of a catheter, the growth was found to come from the posterior wall of the vagina. A strong wire snare, used for removal of uterine polypi, was passed round the growth high up, and the whole tumour removed. No bleeding of consequence followed. The vagina was then washed out with Condy's fluid and water.

September 19th. The temperature rose, and there was some abdominal tenderness. Evening temperature $103.8^{\circ}$ F.; free discharge.

The child died in the night of May 24th, from general peritonitis. Post-mortem examination revealed that general peritonitis was present, and a collection of pus was found in the region of the left ovary, which organ could nut be discovered. The wall of the vagina was intact at the point of attachment of the tumour, and there was no evidence of cellulitis in the neighbourhood of the rectum or elsewhere. Lewis W. MarshaLL, M.D., Surgeon, Children's Hospital, Nottingham.

\section{THERAPEUTIC MEMORANDA.}

\section{IDIOSYNCRASY TO ATROPINE.}

L. N. was admitted to the East Sussex Hospital, Hastings, on the evening of October 5th. The mother gave the following history. The child, who is 5 years old, and has convergent strabismus, had attended a dispensary for ophthalmic cases, and two days before (October 3rd) had been ordered the following treatment: Guttæ atropiæ (gr.iv to $z_{j}$ ) two drops to be put into each eye three times a day. This had been done ten times, so that forty drops of the solution had been used, equivalent to about one-third of a grain of atropine. On the afternoon of October 5th the mother noticed that the child could not stand or sit still, "her legs and arms kept moving about." Later on she got worse, and had a slight convulsive attack.

On admission, face flushed, skin hot and dry ; a bright red erythematous rash covered the front of the chest, abdomen, and arms; pupils widely dilated, the iris being only a thin ring round the pupil; tongue red and dry; complained of being thirsty; hands and feet cold; she could not walk or stand upright; talked loudly and rolled about in bed; took no notice of anyone; temperature 99.2 ${ }^{\circ}$; pulse feeble, 127 .

She was wrapped up in a blanket and mustard applied to the 